\title{
Stability Enhancement of Pleiku Power System using a Distribution Static Synchronous Compensator (D-STATCOM)
}

\author{
Nguyen Thi Mi Sa
}

Hochiminh City University of Technology and Education, Vietnam

\begin{abstract}
This paper presents the simulation results of using a static synchronous compensator (D-STATCOM) based on voltage source converter (VSC) to enhance voltage stability and improve the stability of the actual Pleiku Power System. The PI controller based D-STATCOM is applied to stabilize and improve voltage waveforms at load buses in the studied power system under three-phase short circuit fault. Simulation results in a time domain are presented to show effectiveness of using the D-STATCOM for stability and improvement of voltage quality when small disturbances occur, and of enhancing voltage magnitude, mitigating voltage oscillation in transient conditions under a severe disturbance in the power system.
\end{abstract}

Keywords-D-STATCOM, VSC, PI.

\section{INTRODUCTION}

In recent years, power engineers are increasingly concerned over the stability of the electrical power. Presently in modern industries, load equipment uses electronic controllers which are sensitive to poor voltage quality and will shut down if the supply voltage is and may mal-operate in other ways if harmonic distortion of the supply voltage is excessive. Many efforts have been taken by utilities to fulfill consumer requirement, some consumers require a level of power quality higher than the level provided by modern networks of electricity. It shows that some measures must be taken in order to achieve higher levels of power quality. The Facts devices and Custom power devices are introduced to electrical system to improve the power quality of the electrical power. DVR, STATCOM/D-STATCOM, ACTIVE FILTERs, UPFC, UPQC etc are some of the devices used to improve the power quality of the current and voltage. By the help of these devices we are able to reduce the problems related to power quality. Under this work, among the different custom power devices D-STATCOM has been used to improve the quality of power under different conditions. The general theory about the D-STATCOM operation and its main components is discussed in next part.

D-STATCOM [1] is a voltage source converter (VSC) that is connected in shunt with the distribution system by means of a tie reactance connected to compensate the load current. In general, a coupling transformer is installed between the distribution system and the D-STATCOM for isolating the D-STATCOM from the distribution system. In addition, the device needs to be installed as close to the sensitive load as possible to maximize the compensating capability. Being a shunt connected device, the DSTATCOM mainly injects reactive power to the system.

The role of D-STATCOM is specifically appreciated in case of a weak AC system [2].

Application of D-STATCOM in distribution systems has gained considerable attention. While [3] discusses the dynamic performance of a D-STATCOM coupled with an energy storage system (ESS) for improving the power quality of distribution systems, [4] presents a study about the influences of a D-STATCOM on the dynamic behavior of distribution networks. The performance of a DSTATCOM as a voltage controller or a power factor controller is analyzed in [4].

To provide this voltage support, a D-STATCOM is connected to the micro-grid in [5]. It is well known that a D-STATCOM can provide reactive power support in normal operation. However, it can release the energy stored in it dc capacitor during transients to provide ride through to facilitate load shedding. In [5], the effect of sudden power loss is investigated with and without the DSTATCOM connection. A representative example of DSTATCOM is given in [6]. The goal of this paper is to investigate the main impacts of D-STATCOM on the 
stability performance and protection system of a distribution network. The simultaneous usage of ac generators and D-STATCOM devices is analyzed. The stability studies were carried out using the phasor solution method for network representation, and electromagnetic (EM) transient analysis was employed in the protection studies.

This paper is organized as follows; section 2 presents D-STATCOM model. In section 3, Strategy of controlling D-STATCOM is also carried out in this Section. Then, in section 4 simulation results of D-STATCOM with PI controller in studied system are proposed. Finally, conclusion is discussed in 5 .

\section{THE D-STATCOM SYSTEM CONFIGURATION AND MODELLING}

The structure of D-STATCOM along with its operating modes is shown in Fig. 1. The main components of DSTATCOM are - a VSC (voltage source converter), controller, filter, and energy storage device. The system scheme of D-STATCOM is shown in Fig. 2. These are briefly described as follows:

Isolation transformer: It connects the D-STATCOM to the distribution network and its main purpose is to maintain isolation between the D-STATCOM circuit and the distribution network.

Voltage source converter: A voltage source converter consists of a storage device and devices of switching, generating a sinusoidal voltage at any required frequency, magnitude and phase angle. In the D-STATCOM application, this temporarily replaces the supply voltage or generates the part of the supply voltage which is absent and injects the compensating current into the distribution network depending upon the amount of unbalance or distortion. In this work, an IGBT is used as the switching device.

DC charging unit: This unit charges the energy source after a compensation event and also maintains the dc link voltage at the nominal value.

Harmonic filters: The main function of harmonic filter is to filter out the unwanted harmonics generated by the VSC and hence, keep the harmonic level within the permissible limit. Energy storage unit: Energy storage units like Flywheels, batteries, superconducting magnetic energy Storage (SMES) and super capacitors store energy. It serves as the real power requirements of the system when D-STATCOM is used for compensation [3].
In case, no energy source is connected to the DC bus, then the average power exchanged by the D-STATCOM is zero assuming the switches, reactors, and capacitors to be ideal.

Fig. 3 represents the schematic scheme of DSTATCOM in which the shunt injected current Ish corrects the voltage sag by adjusting the voltage drop across the system impedance Zth and value of Ish can be controlled by altering the output voltage of the converter [4].

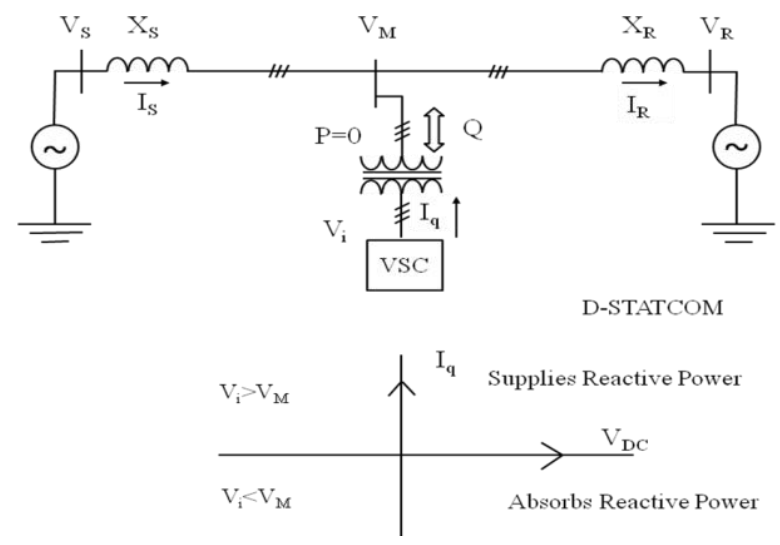

Fig. 1: Structure and operating modes of D-STATCOM

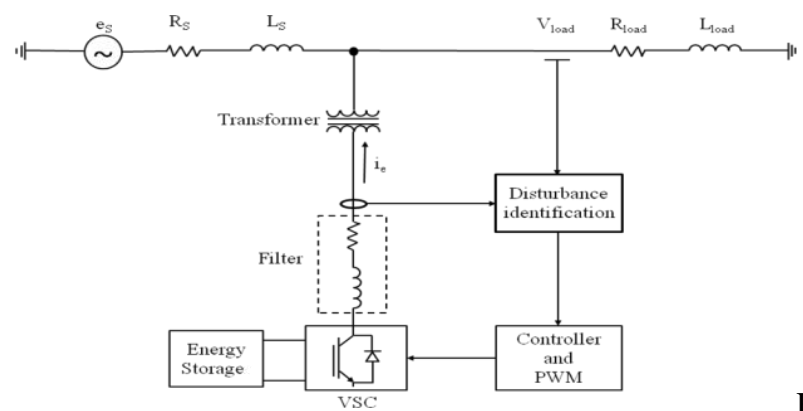

Fig. 2: System scheme of D-STATCOM

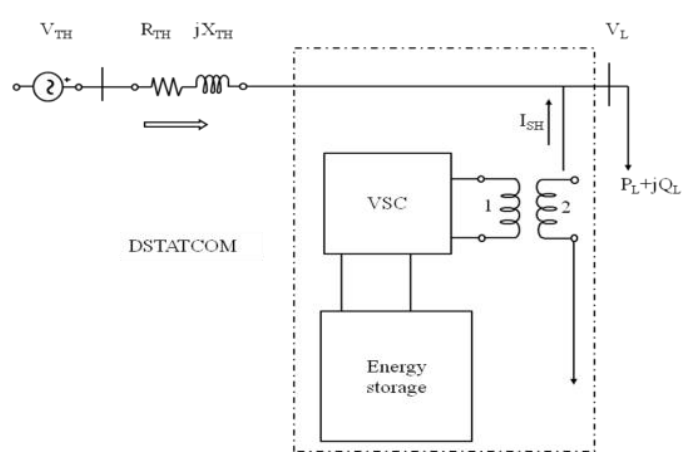

Fig. 3: Schematic diagram of D-STATCOM

The effectiveness of the D-STATCOM in correcting the fault depends on the value of Zth or fault level of the load bus. When the shunt supplied current Ish is set in quadrature with VL, the desired correction of voltage can be achieved without injecting any active power into the system. Alternatively, when the value of Ish is decreased, the same correction of voltage can be achieved with minimum apparent power injection into the system. The 
contribution of the D-STATCOM to the load bus voltage equals the injected current times the impedance seen from the device also, that is the source impedance in parallel with the load impedance. The ability of the D-STATCOM to compensate the voltage dip is limited by this available parallel impedance. It helps to reduce the voltage fluctuations at the PCC (point of common coupling) [5], [6]. Voltage dips can be mitigated by D-STATCOM, which is based on a shunt connected voltage source converter. VSC with pulse-width modulation (PWM) offers fast and reliable control for voltage dips mitigation. The topology of the D-STATCOM connected at distribution level is shown in Fig. 4. In the proposed model, the application of D-STATCOM to improve the power quality in a distribution network with Single Line to Ground (SLG) fault and Double Phase to Ground (DPG) fault and three-phase fault is investigated.

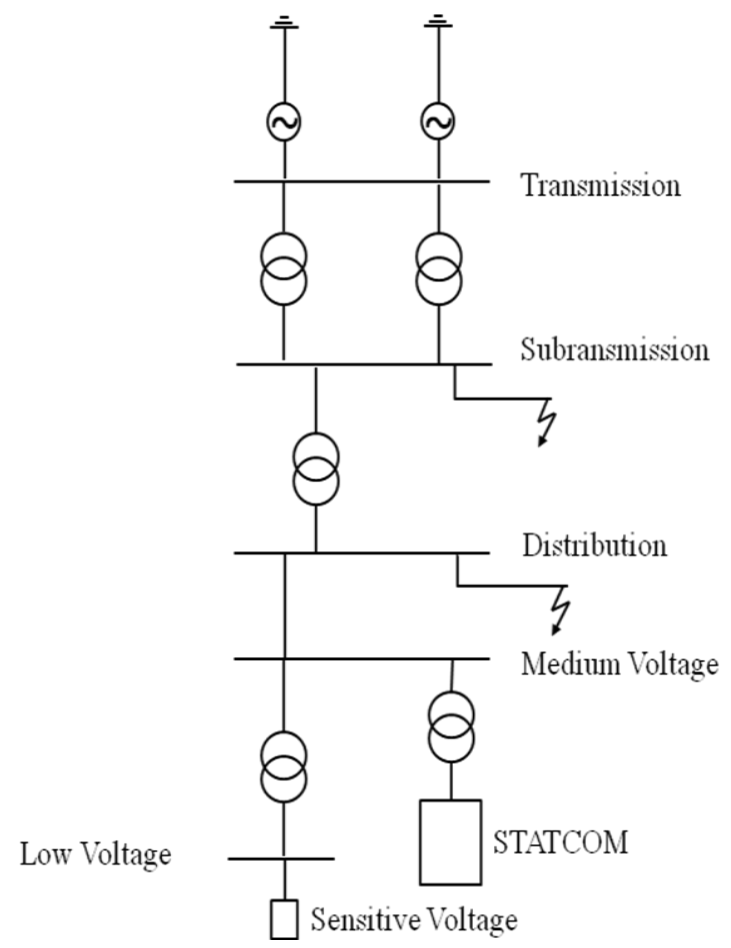

Fig. 4: Topology of the power system with D-STATCOM

\section{STRATEGY OF CONTROLLING D-STATCOM}

The output voltage of the GTO converter (Vi) is controlled in phase with the system voltage (Vs), as shown in this Fig. 5, and the output current of the STATCOM (I) varies depending on $\mathrm{Vi}$. If $\mathrm{Vi}$ is equal to $\mathrm{Vs}$, then no reactive power is delivered to the power system. If $\mathrm{Vi}$ is higher than Vs, the phase angle of $\mathrm{I}$ is leading with respect to the phase angle of Vs by 90 degrees. As a result, leading reactive power flows from the STATCOM (capacitive mode). If $\mathrm{Vi}$ is lower than $\mathrm{Vs}$, the phase angle of $\mathrm{I}$ is lagging with respect to $\mathrm{Vs}$ by 90 degrees. As a result, lagging reactive power flows into the STATCOM (inductive mode). The amount of the reactive power is proportional to the voltage difference between $\mathrm{Vi}$ and Vs. Note that this is the same basic operating principal as a rotating synchronous condenser. Working and V-I characteristic of the STATCOM is shown in Figs. 6-7.

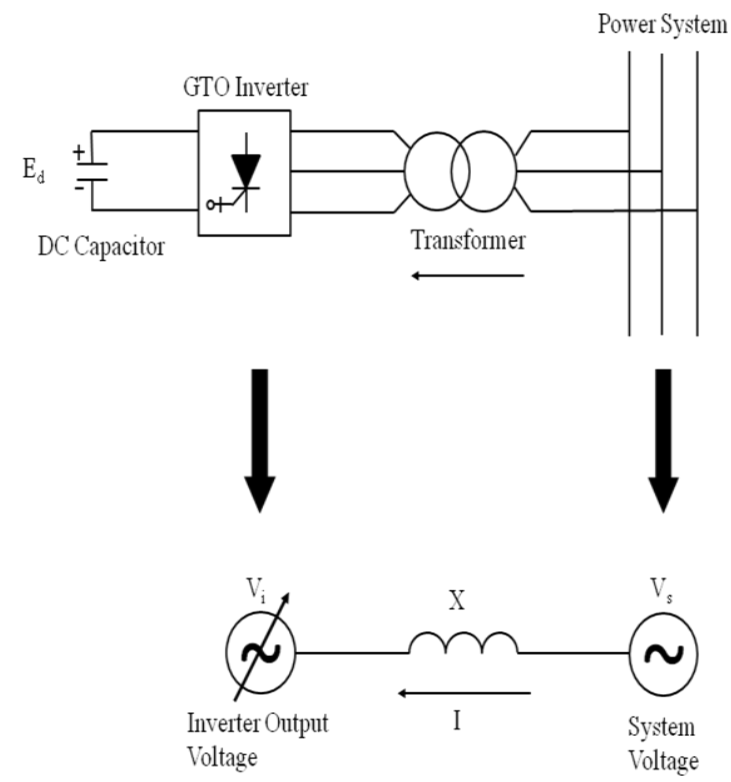

Fig. 5: Control strategy of D-STATCOM

The D-STATCOM smoothly and continuously controls voltage from V1 to V2. However, if the system voltage exceeds a low-voltage (V1) or high-voltage limit (V2), the STATCOM acts as a constant current source by controlling the converter voltage (Vi) appropriately. Thus, when operating at its limits of voltage, the quantity of reactive power compensation provided by the STATCOM is more than the most-common competing FACTS controller, namely the Static Var Compensator (SVC).

\section{D-STATCOM WITH PI CONTROLLER IN PLEIKU POWER SYSTEM}

Fig. 8 shows the test system implemented in MATLAB/SIMULINK to carry out simulations for the DSTATCOM. In this test model, outgoing feeder with two major loads is Nam Hoa (selling electricity through lowvoltage grid) and Nutifood (sold electricity through medium-voltage grid) which is two typical loads according to the voltage level of outgoing feeder.

Suppose that in the case of placing the D-STATCOM device $(22 \mathrm{kV},+/-1 \mathrm{Mvar})$ at the Nutifood node and assuming a short-circuit problem at this node and Nam Hoa 
node [7-11]. D-STATCOM simulation model as shown in Fig. 9.

The comparative transient responses of the studied system with D-STATCOM (presented as blue lines) and without D-STATCOM (presented as red lines) when a three phase fault is simulated at Nam Hoa bus at $\mathrm{t}=0.05$ sec. and cleared after $0.01 \mathrm{sec}$ are plotted in Figs. 10-18.

From these results, it shows that with D-STATCOM, the load bus as well as the capacity of the line are significantly improved when a three-phase short-circuit occurs.

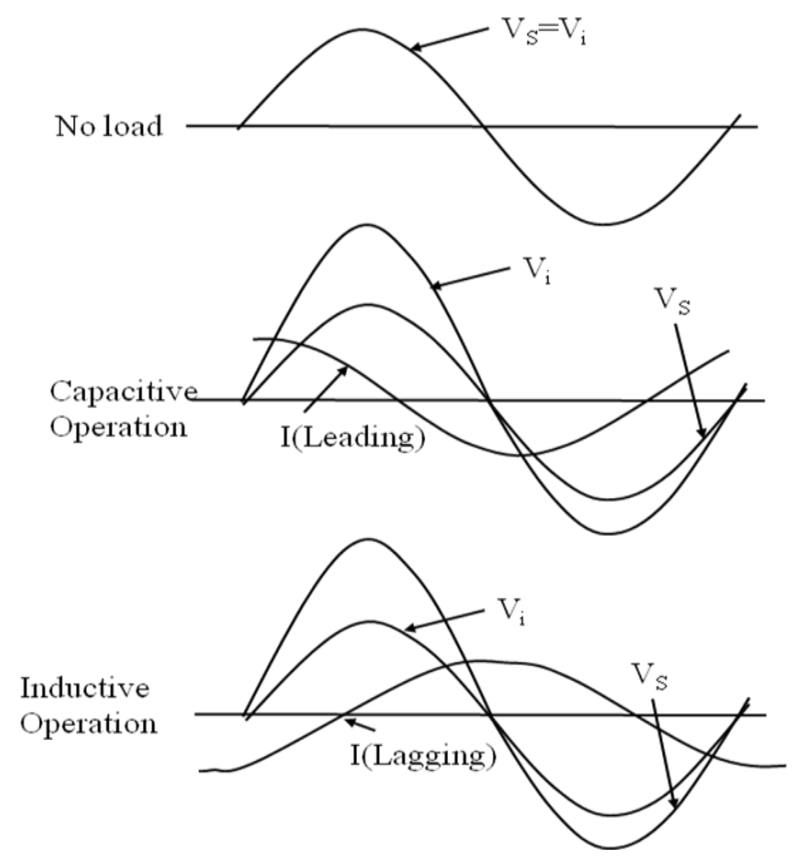

Fig. 6: Working of D-STATCOM

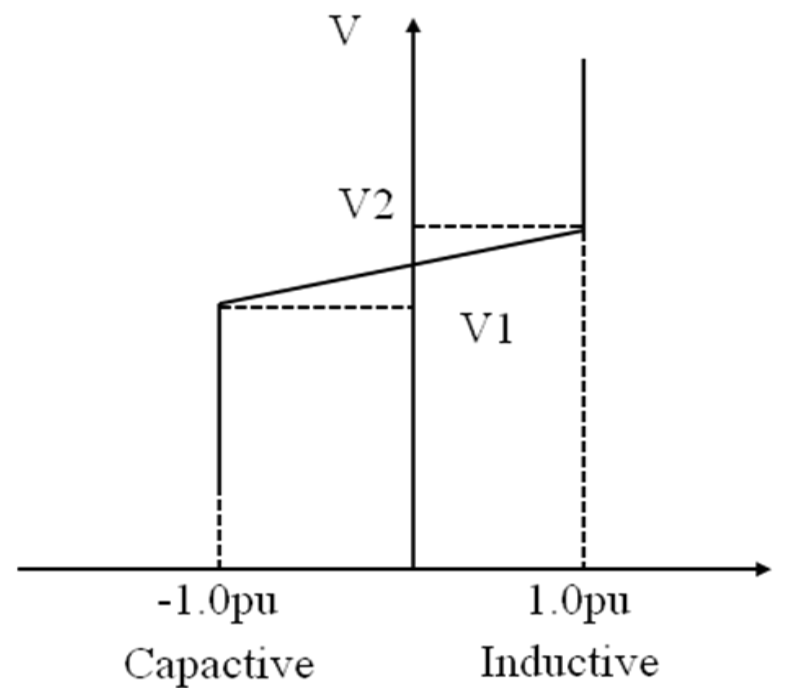

Fig. 7: V-I characteristic of D-STATCOM
필

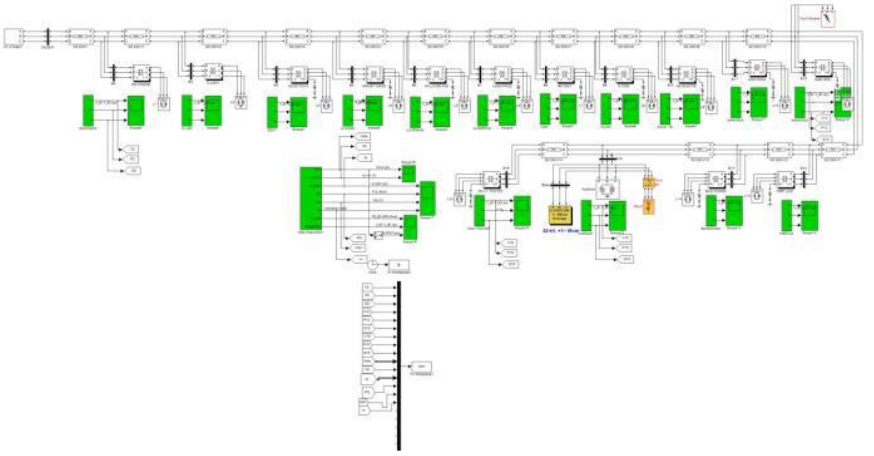

Fig. 8: Simulink model of test system with DTATCOM

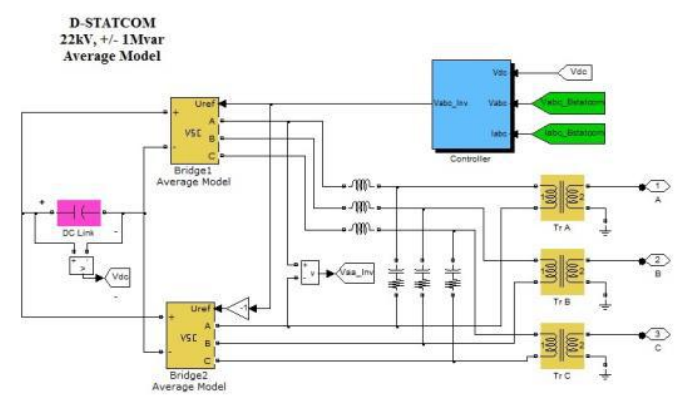

Fig. 9: D-STATCOM simulation model.

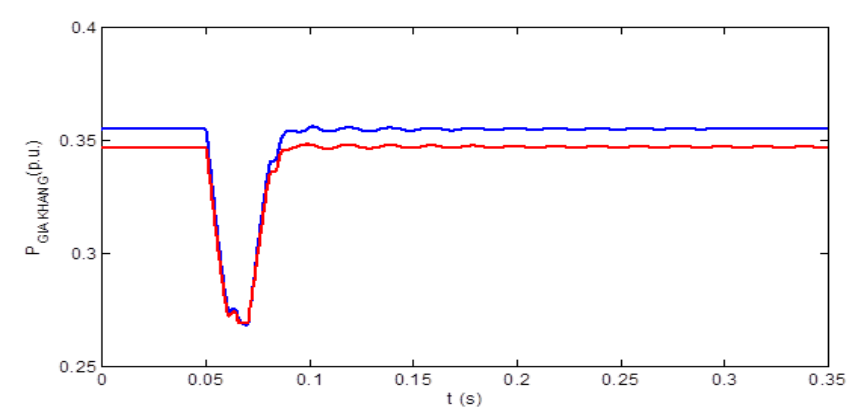

Fig. 10: Gia Khang line active power

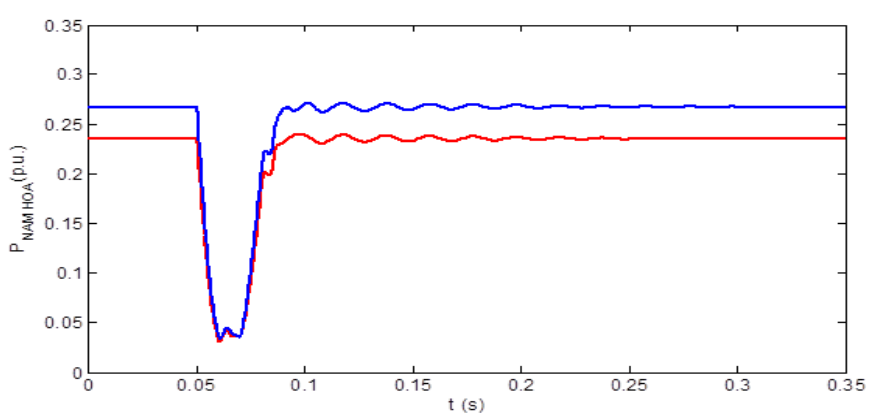

Fig. 11: Nam Hoa line active power 


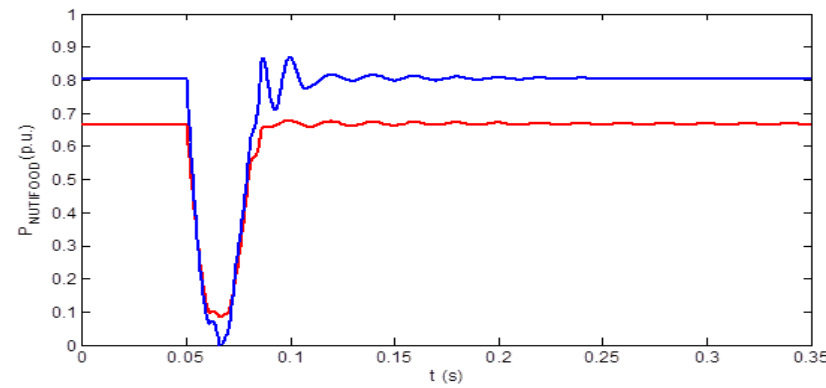

Fig. 12: Nutifood line active power

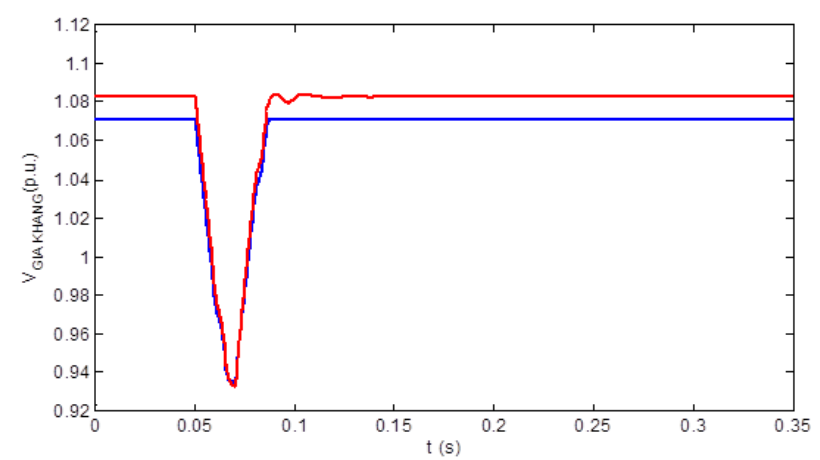

Fig. 13: Gia Khang bus voltage

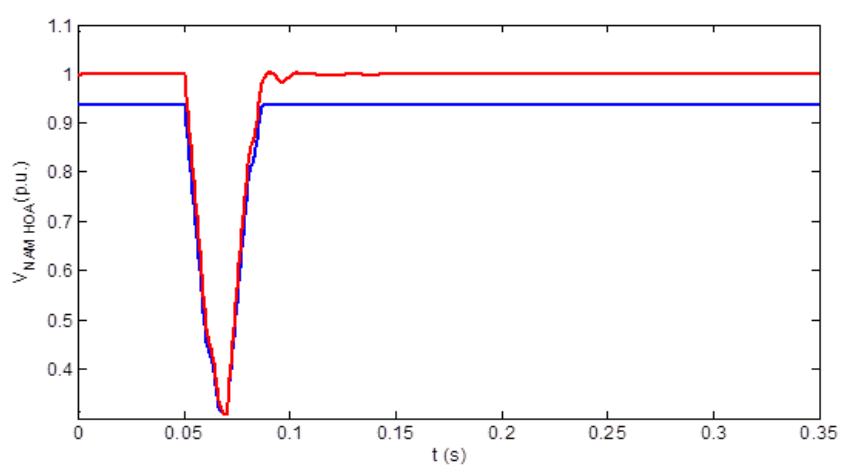

Fig. 14: Nam Hoa bus voltage

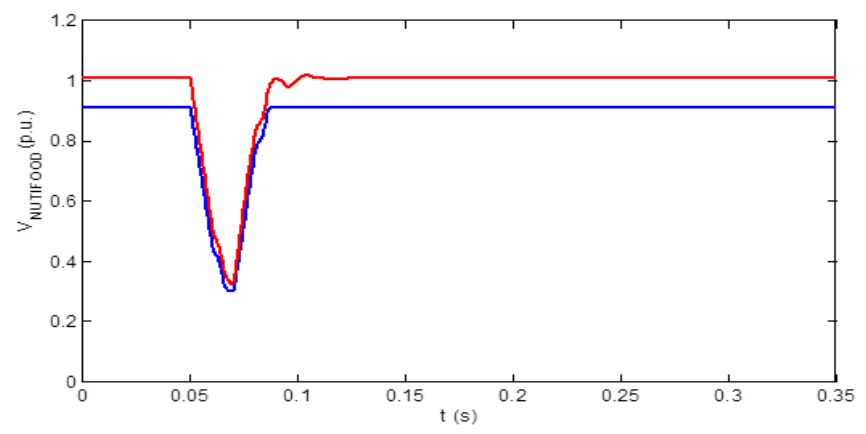

Fig. 15: Nutifood bus voltage

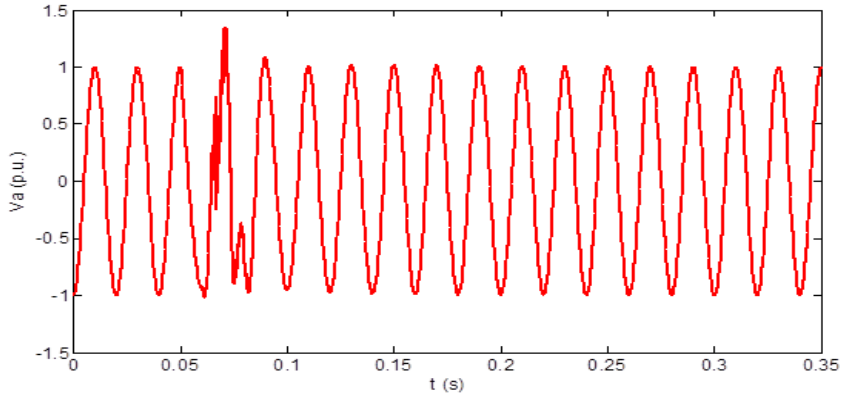

Fig. 16: Reactive power response of D-STATCOM.

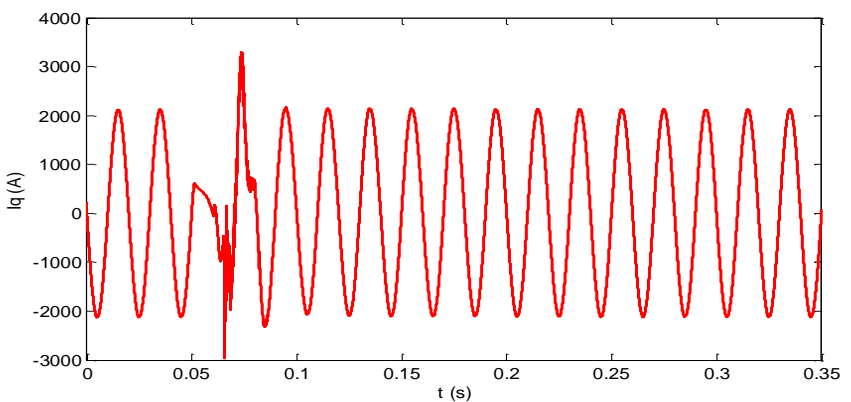

Fig. 17: Curent response of D-STATCOM.

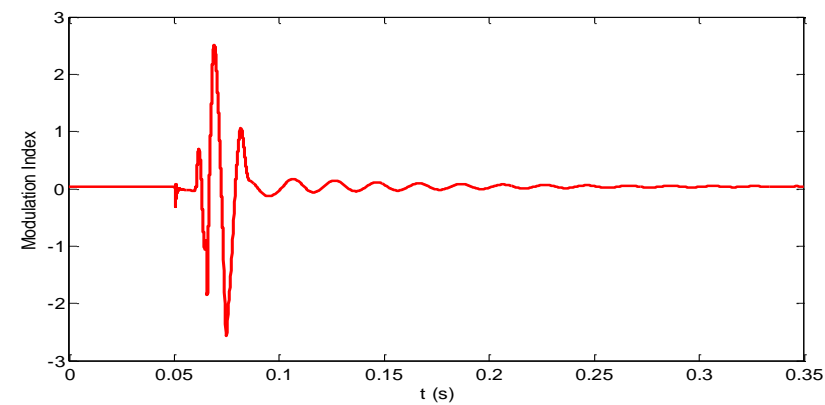

Fig. 18: Modulation coefficient of D-STATCOM

\section{CONCLUSION}

In this work, the investigation on the role of DSTATCOM is carried out to improve the stability in Pleiku distribution networks. Proportional-Integral (PI) controller is used with the device to improve its performance. Test system is analyzed and results are presented in the simulation section. The results shows the satisfactory performance of D-STATCOM in the distribution networks under three-phase fault conditions and it can be concluded that D-STATCOM effectively improves the stability in distribution networks.

\section{ACKNOWLEDGEMENTS}

This research was supported by the HCMC University of Technology and Education. 


\section{REFERENCES}

[1] Jung, S.Y., Kim, T.H., Moon, S. and Han., B.M. 2002. Analysis and control of D-STATCOM for a line voltage regulation. Proceedings of Institute of Electrical and Electronics Engineers Conference on Power Engineering Society Winter Meeting. 12, 729-734.

[2] Ghosh, A. and Ledwich, G. 2003. Load compensating DSTATCOM in weak AC systems. Institute of Electrical and Electronics Engineers Transactions on Power Delivery. 18, 1302-1309.

[3] M.G. Molina and P.E. Mercado, "Control Design and Simulation of D-STATCOM with Energy Storage for Power Quality Improvement," Transmission \& Distribution Conference and Exposition: Latin America, TDC, IEEE/PES, pp 1-7, 2006

[4] W. Freitas, A. Morelato, X. Wilsun and F. Sato, "Impacts of AC Generators and D-STATCOM devices on the dynamic performance of distribution systems," IEEE Trans. On Power Delivery, Vol. 20, No. 2, pp. 1493-1501, 2005.

[5] Ritwik Majumder, Arindam Ghosh, Gerard Ledwich and Firuz Zare, "Enhancing the Stability of an Autonomous Microgrid using D-STATCOM," Fifteenth National Power Systems Conference (NPSC), IIT Bombay, Dec. 2008.

[6] M. SRILATHA, P. NAGESWARA RAO, "Effect of DSTATCOM Devices on the Dynamic Performance of Distribution Networks," International Journal of Advanced Technology and Innovative Research, vol. 7, no. 6, pp. 933937, Jul. 2016.

[7] P. Kundur, Power system stability and control, 2nd ed., USA: Mc Graw-Hill, 1993.

[8] P. M. Anderson and A.A. Fouad, Power System Control and Stability, 2nd ed., USA: Wiley- IEEE Press, 1997.

[9] X. Lei, E.N. Lerch and D. Povh, "Optimization and coordination of damping controls for improving system dynamic performance," IEEE Trans. Power Syst., vol. 16, $473-480,2001$.

[10] E. V. Larsen and D. A. Swann, "Applying power system stabilizers, P-III, practical considerations," IEEE Trans. Power App. Syst., 1981, vol. 100, pp. 3034 - 3046, 1981.

[11] J. G. Douglas and G. T. Heydt, "Power Flow Control and Power Flow Studies for Systems with FACTS Devices," IEEE Trans. Power Syst., vol. 13, 60 - 65, 1998. 